\title{
BMJ Open Assessment of workplace bullying: reliability and validity of an Arabic version of the Negative Acts Questionnaire-Revised (NAQ-R)
}

\author{
Nisrine N Makarem, ${ }^{1}$ Lucy R Tavitian-Elmadjian, ${ }^{2,3}$ Dayana Brome, ${ }^{2}$ \\ Ghassan N Hamadeh, ${ }^{1}$ Ståle Einarsen ${ }^{4}$
}

To cite: Makarem NN, TavitianElmadjian LR, Brome D, et al. Assessment of workplace bullying: reliability and validity of an Arabic version of the Negative Acts QuestionnaireRevised (NAQ-R). BMJ Open 2018;8:e24009. doi:10.1136/ bmjopen-2018-024009

- Prepublication history and additional material for this paper are available online. To view please visit the journal online (http://dx.doi.org/10.1136/ bmjopen-2018-024009).

Received 8 May 2018 Revised 14 August 2018 Accepted 18 October 2018

Check for updates

(C) Author(s) (or their employer(s)) 2018. Re-use permitted under CC BY-NC. No commercial re-use. See rights and permissions. Published by BMJ.

${ }^{1}$ Department of Family Medicine, American University of BeirutMedical Center, Beirut, Lebanon ${ }^{2}$ Department of Psychology, Haigazian University, Beirut, Lebanon

${ }^{3}$ Department of Culture Studies, Tilburg University, Tilburg, The Netherlands

${ }^{4}$ Faculty of Psychology, University of Bergen, Bergen, Norway

Correspondence to Dr Ghassan N Hamadeh; ghamadeh@aub.edu.Ib

\section{ABSTRACT}

Introduction Interest in workplace bullying has been steadily growing since the 1990s, focusing on understanding its driving factors, prevalence rates in different occupations and countries, its consequences, as well as the characteristics of the typical bully and victim. Currently, the Negative Acts Questionnaire-Revised (NAQ-R) is the most frequently used questionnaire to assess workplace bullying. Studies in the Arab world are scarce and to date the NAQ-R has not been validated in Arabic, the official or c0-official language in around 25 countries in the Middle East and Asia. The aim of this study was therefore to develop an Arabic version of NAQ-R. Materials and methods 447 participants aged 18-70 years were recruited through convenient sampling. Exclusion criteria were illiteracy and employment for less than 6 months. Participants were recruited from shops, banks, travel agencies and restaurants in an area in central Beirut around a tertiary care medical centre. A two-stage process was employed to translate the original version of NAQ-R to Arabic. This translated version along with validated Arabic versions of the Satisfaction with Life Scale and the Beck Depression Inventory II were distributed to participants.

Results A 14-item two-factor NAQ-R, with subscales of person-related and work-related bullying, was supported. Reliability coefficients for total and subscale scores of the NAQ-R ranged from 0.63 to 0.90 . The Arabic NAQ-R had good concurrent validity as indicated by significant correlations with depression and satisfaction with life ( $p$ $<0.05)$.

Conclusion NAQ-R was translated to Arabic and adapted. The results revealed acceptable levels of reliability and construct validity. As for the underlying factor structure, it needs to be further supported.

\section{INTRODUCTION}

Workplace bullying is a prevalent problem in many countries. ${ }^{12}$ This phenomenon was first described by the Swedish researcher Heinz Leymann in 1984. He defined workplace bullying as hostile and unethical communication that occurs at least once weekly over a period of at least 6 months. ${ }^{3}$ This form of
Strengths and limitations of this study

- This is the first study to yield an Arabic version of the Negative Acts Questionnaire-Revised (NAQ-R) with acceptable levels of reliability and construct validity.

- The Arabic NAQ-R can be used in more than 25 countries where Arabic is the official/co-official language in addition to assessing workplace bullying among Arabic-speaking immigrants in the West.

- A rigorous methodological process of scale validation was employed including submission of scales to focus groups.

- Response bias due to the sensitivity of the topic and the possible presence of supervisors/managers.

- Caution with generalisability as sample was drawn from one area in central Beirut.

communication aims at harassing, offending, socially excluding someone or negatively affecting someone's work duties. The frequency and duration of bullying is essential to its definition because, as described by Einarsen, Hoel and Cooper, bullying is an escalating process which progressively results in undermining the victim. ${ }^{4}$ Another central feature to the definition of bullying is an imbalance of power of the two parties involved; the victim and the bully. This discrepancy limits the victim's ability for self-defence and revenge. ${ }^{5}$ The term 'mobbing at work' has been used in some Scandinavian and German countries to refer to the concept of workplace bullying. ${ }^{3}$

Workplace bullying has been associated with a number of negative outcomes relating to the individual, co-workers witnessing the situation, and the organisation itself. Studies have indicated a negative relationship between workplace bullying and psychological health ${ }^{67}$ as well as overall life satisfaction ${ }^{8}$ for both victims and observers. ${ }^{9}$ Specifically, bullying victims have been found to have increased rates of depression, ${ }^{10}{ }^{11}$ anxiety, ${ }^{11}$ 
post-traumatic stress disorder, ${ }^{12}{ }^{13}$ elevated risk of suicide, ${ }^{14}$ sleep problems, ${ }^{7}$ burn-out, ${ }^{15}$ psychosomatic health complaints, ${ }^{6}$ as well as musculoskeletal complaints ${ }^{16}$ and fibromyalgia. ${ }^{17}$

At the organisational level, bullying incurs costs, affects productivity and reputation, and alters an organisational culture to one of fear and hostility. Studies have shown that workplace bullying leads to high job dissatisfaction, ${ }^{18}$ staff turnover, ${ }^{19}$ as well as increased rates of sick leaves. ${ }^{20}$

In light of such repercussions and considering the fact that a sizeable number of workers at some point in their careers will be exposed to workplace bullying either directly as targets or indirectly as bystanders, ${ }^{4}$ studying the prevalence of workplace bullying becomes of paramount importance within most organisational contexts. The importance of such research is even more pronounced in settings where workplace bullying is expected to be elevated as a function of cultural values stressing a differential distribution of power, a dimension termed power distance in Hofstede's cultural dimension theory. ${ }^{21}{ }^{22}$ Since Arab countries have high scores on this cultural dimension, workplace bullying might be highly prevalent and even accepted. Hence, it is of utmost importance to study the prevalence of bullying in an Arab context. Considering the lack of a valid tool in the Arabic language, such efforts remain halted. Therefore, the main aim of the present research is to adapt a workplace bullying assessment tool, the Negative Acts Questionnaire-Revised (NAQ-R) in Arabic. Currently, NAQ-R is the most frequently used questionnaire to assess workplace bullying. ${ }^{1}$

To the best of our knowledge, only a handful of studies have so far investigated the prevalence of workplace violence in the Arab world and most have been conducted within the healthcare sector. In a Lebanese study among a sample of nurses, as many as $62 \%$ were exposed to verbal abuse, ${ }^{23}$ and another study reported four in five emergency department workers fall victim to verbal abuse and as many as one in four to physical assault. ${ }^{24}$ Although scarce, similar findings on workplace bullying have been noted in other countries of the Arab World such as Kuwait, Egypt and Saudi Arabia. ${ }^{25-27}$ That said, it is noteworthy that these existing studies seem to have relied on self-report instances of bullying without the use of a known and valid instrument for measuring workplace bullying.

\section{Cultural variations in workplace bullying}

Based on the existing literature, research on workplace bullying has shown that its prevalence is comparatively lower in Scandinavian countries as compared with the rest of Europe, USA and Australia. ${ }^{28} 29$ Such variations seem to support the contention that a particular cultural context influences the degree of perpetuation of workplace bullying. ${ }^{30}$ Hofstede's cultural dimension theory indicates that national culture is composed of four dimensions: power distance, individualism versus collectivism, masculinity versus femininity, and uncertainty avoidance. These in turn influence workplace values, and thus workplace behaviours. ${ }^{31}$ Therefore, the prevalence and perpetuation of workplace bullying can be strongly influenced by the degree to which the national culture and hence the organisational culture accept power and hierarchical structures. ${ }^{32}$ For instance, a cross-cultural study found that the rate of workplace bullying in Portugal was twice that of the rate in the UK $(33.5 \%$ and $15.4 \%$, respectively). ${ }^{33}$ This difference may be explained in terms of the high score of Portugal on power distance compared with the UK, reflecting the existence of a hierarchical structure with those in the most powerful positions being more privileged. ${ }^{34}$

\section{Negative Acts Questionnaire-Revised}

One of the most widely used questionnaires in research to assess the presence of workplace bullying is the NAQ ${ }^{35-41}$ The NAQ was developed and revised with the aim of becoming a standardised research tool for measuring exposure to workplace bullying. ${ }^{42}$ The original 23-item questionnaire was developed based on literature review and case studies and included negative acts related to personal and work-related aspects. ${ }^{35}$ Due to certain shortcomings of this original scale, the NAQ-R was developed and proposed as a free 22-item questionnaire for use in non-commercial research projects worldwide. ${ }^{42}{ }^{43}$ In addition to the 22 items, the NAQ-R includes 12 items that address the frequency and nature of bullying if it occurs. ${ }^{42}$ The NAQ-R is used in more than 100 ongoing research projects around the world and has been translated to many languages. Data yielded from projects employing NAQ-R are gathered by the Bergen Bullying Research Group (a research team at the University of Bergen in Norway) in an international database called the International Database on the Prevalence and risk factors of Bullying at work. ${ }^{2}$

\section{The present study}

The present study aimed to adapt NAQ-R in Arabic. This endeavour was guided by a number of considerations; first, Arabic is an official language in Lebanon and the Arab region, and as stated previously, cultural context (national and organisational cultures) seems to play a significant role in influencing the perpetuation of workplace bullying. ${ }^{30}$ Hence, applying the NAQ-R to an Arab (Lebanese) milieu will provide evidence on whether this instrument is useful in assessing bullying in this particular cultural context, especially that the NAQ-R is primarily directed to the Anglo-American culture. ${ }^{42}$ Second, an Arabic version of the NAQ-R can provide more accurate results regarding the prevalence of workplace bullying among Arabic speaking employees. Third, assessing the accurate prevalence of workplace bullying in the Lebanese context will help provide baseline data; thus, presenting scholars, leaders and managers with background information that can be used to devise prevention and intervention strategies. Fourth, a validated Arabic scale could be administered to Arabic-speaking immigrants in the West, considering that immigrants are more likely than natives to label themselves as bullied. ${ }^{44}$ Last but not least, 
for further research in the Arab world on the antecedents, risk factors and outcomes on workplace bullying, a validated tool to measure bullying is needed.

With the aim of the current study to develop an Arabic version of NAQ-R, the following sections will depict the examination of the factor structure, reliability and predictive validity of the Arabic-translated NAQ-R by employing a sample of Lebanese employees. The results of the study will be discussed in light of the limitations and strengths that pertain to the study. For the purpose of assessing the concurrent validity of the Arabic version of NAQ-R, the correlation between NAQ-R and each of depression, life satisfaction and number of sick leaves, was investigated. This is based on the literature's depiction of an existing relationship between workplace bullying and decreased level of overall life satisfaction, ${ }^{8}$ increased rates of depression $^{1011}$ and increased rates of sick leaves. ${ }^{20}$

\section{SUBJECTS AND METHODS Subjects}

A total of 447 participants aged 18-70 years, employed for a minimum of 6 months, were recruited through convenience sampling. Those who are illiterate and employed for less than 6 months were excluded from the study. The exclusion of those who are employed for less than 6 months is attributed to the definition of workplace bullying which points to one's exposure to hostile and unethical communication that occurs at least once weekly over a period of at least 6 months. ${ }^{3}$

We calculated the sample size for this study based on specifying a certain number of observations per number of parameters that must be estimated. ${ }^{45}$ Using this approach, two parameters can be estimated per variable/ item, namely a factor loading and an error variance. If 10 participants are estimated per parameter, then 20 participants are estimated per item bringing the total of participants needed to 440 . Assuming a $10 \%$ contingency rate, an additional 44 participants were added, and the resulting number was rounded up to 500 target participants. Participants were sampled from an area in central Beirut from individual shops, banks, travel agencies and restaurants. The study aims were introduced briefly by the data collectors and a consent form was provided detailing confidentiality and explaining the participant's right to decline participation. The next day, the questionnaires were collected from the employees. No funding was needed, and no additional data are available. Sociodemographic characteristics of the sample are presented in table 1 .

\section{Methods}

We employed a survey design to address the psychometric properties of NAQ-R. Three questionnaires, an Arabic translation of the NAQ-R, the Arabic version of the Beck Depression Inventory II (BDI-II) ${ }^{46}$ and the Arabic Satisfaction with Life Scale (SWLS) ${ }^{47}$ were administered to the participants in counterbalanced order with the three
Table 1 Individual demographic characteristics as a percentage of the sample $(n=447)$

\begin{tabular}{lc}
\hline Characteristics & N (percentage) \\
\hline Sex & \\
Male & $189(42.3)$ \\
Female & $238(52.3)$ \\
Unknown & $20(4.5)$ \\
Employment type & \\
\hline Full-time & $354(79.2)$ \\
\hline Part-time & $46(10.3)$ \\
\hline Unknown & $44(9.8)$ \\
Highest education level & \\
\hline Primary & $18(4)$ \\
\hline Secondary & $67(15)$ \\
\hline University/technical & $238(53.2)$ \\
\hline Graduate/postgraduate & $84(18.8)$ \\
\hline Unknown & $40(8.9)$ \\
\hline Chronic illness & \\
\hline Yes & $40(8.9)$ \\
\hline No & $354(79.2)$ \\
\hline Unknown & $49(11)$ \\
\hline Number of sick leave in days & \\
\hline 0 & $153(34.2)$ \\
\hline $1-5$ & $212(47.4)$ \\
\hline $6-10$ & $40(8.9)$ \\
\hline$>10$ & $18(4)$ \\
\hline Unknown & $24(5.4)$ \\
\hline & \\
\hline
\end{tabular}

questionnaires arranged in different orders. A short form inquiring about demographic factors such as age, sex and number of sick leaves was administered at the end of the survey. For obtaining concurrent validity evidence, the relationship between NAQ-R scores and overall life satisfaction as measured by SWLS ${ }^{48}$ and depression as measured by $\mathrm{BDI}^{49}$ was examined. We hypothesised that high scores on NAQ-R would correlate positively with depression $^{67}$ and negatively with satisfaction with life. ${ }^{8}$ We also hypothesised that high scores on NAQ-R would correlate positively with the number of absences related to sick leaves. ${ }^{50}$

\section{INSTRUMENTS}

\section{The Arabic NAQ-R}

We translated the original English version of the NAQ-R to Arabic employing a two-stage process. First, three bilingual specialists, fluent in Arabic and English, applied the back-translation method to translate the NAQ-R to Modern Standard Arabic. Discrepancies between the original and back-translated versions were addressed using the committee approach and appropriate changes were made. Next, we administered the Arabic NAQ-R to 
two groups of participants. The first group comprised 10 bilingual (English and Arabic speaking) participants and the other comprised 10 strictly Arabic speaking participants. After completing the scales, we discussed the clarity, cultural relevance and flow of the items in the two focus groups. We adopted this process to clarify whether the translated scale is equivalent in meaning to the English version and is free of any bias that might have been introduced by the translators due to their knowledge of the English language. We then took into account suggestions that ensued from the two focus groups and conducted changes accordingly (see on-line supplementary appendix).

\section{The Arabic BDI-II}

This is an Arabic translation of the 21-item BDI-II, ${ }^{49}$ which is a self-report rating inventory that measures characteristics, attitudes and symptoms of depression. The Arabic adaptation has acceptable internal consistency with alpha coefficients ranging from 0.67 to $0.89 .^{46}$

\section{Satisfaction with Life Scale}

The Arabic translation of the five-item SWSL, designed to measure global cognitive judgements of one's life satisfaction, was used. ${ }^{48}$ Participants indicate how much they agree or disagree with each of the five items using a 7-point scale that ranges from 7-strongly agree to $1-$ strongly disagree. The Arabic translation of SWLS has acceptable reliability estimates with Cronbach's $\alpha$ ranging between 0.73 and $0.79 .{ }^{47}$

\section{Overview of statistical analyses}

We applied independent samples t-tests as well as univariate analyses of variance to examine differences on the NAQ-R total and subscale scores across demographic variables of gender, employment type, employment duration, number of sick leaves per year, and presence of chronic illness.

Concurrent validity was assessed through examining Pearson's correlations between bullying symptoms of depression and overall satisfaction with life. Reliability of the Arabic NAQ-R was assessed through Cronbach's $\alpha$.

Since the NAQ-R's three-factor solution has been theoretically and empirically supported, ${ }^{42}$ we applied a confirmatory factor analysis using maximum likelihood estimation to test the factor structure in the Arabic NAQ-R. Model fit was assessed through the $\chi^{2}$ test but since it is known that with large samples the $\chi^{2}$ test yields significant results regardless of fit, we assessed other fit indices namely the Goodness-Of-Fit Index (GFI), the Adjusted Goodness-Of-Fit Index (AGFI), the Comparative Fit Index (CFI) and the root mean square error of approximation (RMSEA). The criteria applied to assess the adequacy of the model were as follows: GFI and AGFI $>0.9$, CFI $>0.95$ and RMSEA $<0.08 .^{51}$ Since the three tested models were not good fits for the data, we moved on to exploratory analyses. We applied cross-validation ${ }^{52}$ to assess the factor structure of the Arabic NAQ-R. After randomly splitting the data into two roughly equal halves, we applied exploratory factor analysis (EFA) extracting factors with eigenvalues greater than 1.0 with oblique rotation on the first half and then applied CFA on the second half using the factor structure emerging from the EFA. Data cleaning and analysis were conducted using SPSS V.19, AMOS and R packages.

\section{Patient and public involvement}

No patients/public individuals were involved in setting the research questions nor in developing plans for design or implementation of the study. No patients/public individuals were asked to advise on interpretation or writing of results. There are no plans to disseminate the results of the research to study participants or the relevant public community.

\section{RESULTS}

\section{Scale descriptive}

The characteristics associated with bullying are summarised in table 2. Of the 432 participants, the vast majority $(69 \%)$ reported that they have never been bullied. By far, most respondents reported to be bullied sometimes or more rarely. Of those who endorsed the self-labelling item on seeing oneself as being bullied, $15.7 \%$ identified a manager/supervisor as the source of bullying, $13.7 \%$ identified co-workers as the bullies, while only $4.2 \%$ and $3.2 \%$ reported being bullied by clients and subordinates, respectively. Few participants reported that the bullying was directed only at them $(2.3 \%)$ and that they witnessed bullying at the workplace frequently $(2.8 \%)$.

Next, we examined differences on the NAQ-R total as well as its three subscales (see table 3) based on gender, work type, presence of chronic illness, education level and number of sick leaves in the past year. We found no differences on the NAQ-R total and subscale scores between men and women and between those who have a chronic illness versus those who do not ( $p>0.05$ for all). Scores on the NAQ-R total $(t(74.91)=-2.65, \mathrm{p}=0.01$, full-time $M=1.43, S D=0.45$ vs part-time $M=1.3, S D=0.28)$, person-related bullying subscale $(t(73.7)=-2.63, \mathrm{p}=0.01$, full-time $M=1.41, S D=0.49$ vs part-time $M=1.27, S D=0.31)$ and physically threatening behaviour subscale $(t(139.83)=-4.58$, $\mathrm{p}<0.01$, full-time $M=1.23, S D=0.49$ vs part-time $M=1.1$, $S D=0.16)$ were significantly different based on employment type. For all three subscales, participants employed on a full-time basis scored higher than those employed on a part-time basis. Only scores on the physically threatening behaviour were significantly different across education level $(F(3,390)=3.55, \mathrm{p}=0.01)$ such that those having a high school degree $(M=1.34, S D=0.48)$ scored higher than those with a university/technicaldegree $(M=1.16$, $S D=0.31)$. Scores on the total NAQ-R $(F(3,406)=10.66$, $\mathrm{p}<0.01)$ as well as its corresponding subscales of work-related bullying $(F(3,406)=6.17, \mathrm{p}<0.01)$, person-related bullying $(F(3,406)=12.01, \mathrm{p}<0.01)$ and physically 
Table 2 Characteristics associated with bullying as assessed by the Negative Acts QuestionnaireRevised (NAQ-R) ( $n=447)$

\begin{tabular}{|c|c|}
\hline Characteristics & $N$ (percentage) \\
\hline \multicolumn{2}{|l|}{ Bullied at work } \\
\hline No & $298(69)$ \\
\hline Yes, rarely & $46(10.6)$ \\
\hline Yes, sometimes & $39(9)$ \\
\hline Yes, several times a week & $10(2.3)$ \\
\hline Yes, almost daily & $2(0.5)$ \\
\hline Unknown & $37(8.6)$ \\
\hline \multicolumn{2}{|l|}{ Start of bullying } \\
\hline Within the last 6 months & $23(5.3)$ \\
\hline Between 6 months and 12 months ago & $41(9.5)$ \\
\hline Between 1 year and 2 years ago & $15(3.5)$ \\
\hline More than 2 years ago & $18(4.2)$ \\
\hline Not applicable & $297(68.8)$ \\
\hline Unknown & $38(8.8)$ \\
\hline \multicolumn{2}{|l|}{ Identity of the bully } \\
\hline Supervisor & $68(15.7)$ \\
\hline Co-worker & $59(13.7)$ \\
\hline Client/student & $18(4.2)$ \\
\hline Subordinate & $16(3.7)$ \\
\hline \multicolumn{2}{|l|}{ Number of people bullied } \\
\hline Only you & $10(2.3)$ \\
\hline You and several others & $71(16.4)$ \\
\hline Everyone at work & $12(2.8)$ \\
\hline Not applicable & $297(68.8)$ \\
\hline Unknown & $42(9.7)$ \\
\hline \multicolumn{2}{|l|}{ Witness bullying at work } \\
\hline Never & $5(1.2)$ \\
\hline Yes, but & $34(7.9)$ \\
\hline Yes, sometimes & $41(9.5)$ \\
\hline Yes, most of the time & $12(2.8)$ \\
\hline Not applicable & 296 (68.5) \\
\hline Unknown & $44(10.2)$ \\
\hline
\end{tabular}

threatening behaviour $(F(3,406)=4.13, \mathrm{p}=0.007)$ significantly differed across number of sick leave days. Follow-up post hoc comparisons showed that those who had not taken any sick leaves scored lower than those who reported having taken sick leaves. As hypothesised, those exposed to workplace bullying reported a higher number of sick leaves. Also, the NAQ-R total scores showed a positive correlation with depression and a negative correlation with life satisfaction.

\section{Concurrent validity}

We examined the correlation between the Arabic NAQ-R total and subscale mean scores and satisfaction with life as assessed by the Arabic SWLS and depressive symptoms as assessed by the Arabic BDI-II (table 3). NAQ-R total scores were negatively correlated with satisfaction with life $(r=-0.34, \mathrm{p}<0.01)$ and positively correlated with depression $(r=0.5, \mathrm{p}<0.01)$. Satisfaction with life was also negatively correlated with all subscales of the NAQ-R (work related $r=-0.28, \mathrm{p}<0.01$, person related $r=-0.33$, $\mathrm{p}<0.01$, physically threatening behaviour $r=-0.24, \mathrm{p}<0.01$ ) while depression was positively correlated with all three subscales (work related $r=0.42, \mathrm{p}<0.01$, person related $r=0.47, \mathrm{p}<0.01$, physically threatening behaviour $r=0.4$, $\mathrm{p}<0.01)$.

\section{Reliability and factor structure of the 22-item Arabic NAQ-R Reliability analysis}

Internal consistency for the Arabic NAQ-R and its subscales was assessed through Cronbach's $\alpha$ and is presented in table 4. Reliabilities were generally acceptable and no increase in the $\alpha$ level for the total scale as well as its subscale was associated with the deletion of items.

\section{Confirmatory factor analysis}

Since the one-factor, two-factor and three-factor solutions have all been associated with acceptable fit indices, ${ }^{42}$ we tested three distinct measurement models; one assuming a one-factor solution of the construct 'workplace bullying', another assuming a two-factor solution of 'work related' and 'person related' bullying and finally a model assuming a three-factor solution with work-related bullying, person-related bullying, and physical intimidation.

Table 3 Scale descriptive

\begin{tabular}{llcll} 
& N & M (SD) & Minimum & Maximum \\
\hline NAQ-R total & 432 & $1.41(0.44)$ & 1 & 3.86 \\
$\quad$ Work related & 432 & $1.55(0.60)$ & 1 & 4.43 \\
Person related & 432 & $1.4(0.48)$ & 1 & 4.27 \\
$\quad$ Physically threatening & 432 & $1.21(0.41)$ & 1 & 5 \\
Satisfaction with life & 394 & $4.21(1.45)$ & 1 & 7 \\
Beck Depression Inventory & 365 & $0.49(0.49)$ & 0 & 2.33 \\
\hline
\end{tabular}

NAQ-R, Negative Acts Questionnaire-Revised. 
Table 4 Internal consistency of the 22-item Arabic Negative Acts Questionnaire-Revised (NAQ-R)

\begin{tabular}{llcl}
\hline & N & N items & Cronbach's $\boldsymbol{\alpha}$ \\
\hline NAQ-R total & 432 & 22 & 0.90 \\
\hline Work related & 432 & 7 & 0.80 \\
Person related & 432 & 12 & 0.89 \\
$\begin{array}{l}\text { Intimidation and } \\
\text { physical threats }\end{array}$ & 432 & 3 & 0.63 \\
\hline
\end{tabular}

\section{Model fit}

After checking the unstandardised parameter estimates for observed variables, variances and covariances, estimates for the three models were associated with a probability value of $\mathrm{p}<0.05$ and adequate standard errors. First, we assessed the associated $\chi^{2}$ values for the one-factor $\left(\chi^{2}\right.$ $(209)=1345.208, \mathrm{p}=0.000)$, two-factor $\left(\chi^{2}(208)=1192.166\right.$, $\mathrm{p}=0.000)$ and three-factor models $\left(\chi^{2} \quad(206)=1222.632\right.$, $\mathrm{p}=0.000)$. The results indicate that the hypothesised models are not entirely adequate.

The GFI and AGFI for all the three models tested were also inadequate (one-factor solution: GFI $=0.757$ and AGFI $=0.706$; two-factor solution: $\mathrm{GFI}=0.79$ and AGFI $=0.745$; three-factor solution: $\mathrm{GFI}=0.783$ and AGFI=0.734). Although these values seem to be close to 1 , it is customary to accept values greater than 0.9 as adequate. $^{51}$

Considering values close to 0.95 as adequate, the CFI in our study was 0.701 for the one-factor solution, 0.741 for the two-factor solution and 0.733 for the three-factor solution. All values are below 0.95 and thus indicative of poor fitting models. RMSEA also indicated poor fit with values of $0.112,0.105$ and 0.107 for the one-factor, two-factor and three-factor solutions, respectively. ${ }^{51}$

Factor loadings on all the three models tested were predominantly below 0.7 . The only item with a factor loading of 0.70 was item 17 'Having allegations made against you' on the one-factor solution model. On the two-factor solution model, items 13 and 17 had loadings of 0.7 and 0.72 , respectively, on person-related bullying; similarly item 17 had a loading on 0.71 on the person-related bullying factor within the three-factor solution model. All three models had some cross-loading items as well as error correlations. The correlation between person-related and work-related bullying in both the models assuming two factors $(r=0.76)$ and three factors was high $(r=0.78)$. In the model assuming three factors person-related bullying and physically intimidating bullying were highly correlated $(r=0.8)$, however the correlation between work-related and physically intimidating bullying $(r=.55)$ was more moderate.

\section{Exploratory factor analysis}

An initial unrestricted EFA for a sample of 226 participants of 22 items of the Arabic NAQ using oblique rotation revealed a five-factor model accounting for $63.52 \%$ variance. However, compared with the first factor $(38.07 \%$ variance) the remaining four factors accounted for a relatively low percentage ranging from $4.9 \%$ for the fifth factor to $8.45 \%$ for factor 2 . On examining the points of inflexion on the scree plot three points of inflexion were observed, with two being more pronounced, therefore we applied a three-component factor analysis.

The resulting rotated matrix revealed three factors with a $53.34 \%$ variance explained. Item loadings ranged from poor $(0.31)$ to excellent $(0.83)$. Four items $(11,19,20$, 22) loaded on more than one factor. Considering the double loadings and the presence of only one item in factor 3 that also loaded on factor 1, it seemed as though a two-factor solution would fit the data. As a follow-up, we repeated the EFA without the items that had multiple loadings on the restricted three-factor solution (items $11,19,20,22)$. Results of the restricted EFA with the remaining items yielded a two-factor solution with $49 \%$ variance explained (see table 5 ).

\section{Follow-up confirmatory factor analysis}

Following up on the findings from our EFA, we conducted a CFA specifying two factors. The resulting model yielded the following results: GFI $=0.862<0.9$, AGFI $=0.824<0.9$, CFI $=0.829<0.95$ and RMSEA $=0.09>0.08$. On examining the standardised estimates, two-item loadings were less than 0.55 and were therefore eliminated from the model. The resulting 14 -item model was tested again, yielding acceptable fit indices for the GFI $=0.916>0.9$ and RMSEA $=0.07<0.08$ with marginally acceptable indices for the AGFI $=0.882<0.9$ and $\mathrm{CFI}=0.9<0.95$. The resulting factor solution is presented in table 6 .

\section{DISCUSSION}

The aim of our study was to assess the psychometric properties of the Arabic translation of NAQ-R. Reliability analyses of the Arabic NAQ-R revealed good internal consistency coefficients for the total score and subscale score. Similar results were also obtained for the Greek version of the NAQ-R where Cronbach's $\alpha$ was $0.915 .{ }^{53} \mathrm{In}$ the Italian validation of a 17 -item NAQ-R, internal consistency was still high for the total NAQ-R score 0.91 and for its two subscales person-related (0.91) and work-related $(0.70)$ bullying. ${ }^{54} \mathrm{~A}$ similarly high internal consistency of 0.91-0.95 was obtained for the Japanese version of the NAQ-R. ${ }^{55}$ These high reliabilities of the translated versions of NAQ-R are compatible with the original NAQ-R Scale. $90 .{ }^{42}$ Therefore, it can be concluded that this study obtained a reliable Arabic version of the NAQ-R. Yet, such a high $\alpha$ indicates that a shorter version could be developed.

In line with the latter, findings from the confirmatory factor analysis revealed two factors with nine and five items, respectively. The analysis first suggested that the factors suggested in the original version ${ }^{43}$ yielded poor fit indices. As such, we used cross-validation as a follow-up to assess the underlying factor structure of the Arabic NAQ-R. Our results supported a two-factor solution with moderate to acceptable 
Table 5 Factor loadings for the two-factor restricted Negative Acts Questionnaire-Revised (NAQ-R) excluding double loading items

\begin{tabular}{|c|c|c|c|}
\hline Factors & & Items & Factor loadings \\
\hline \multirow{3}{*}{$\begin{array}{l}\text { Work } \\
\text { bullying }\end{array}$} & 1. & Someone withholding information which affects your performance & 0.596 \\
\hline & 3. & Being ordered to do work below your level of competence & 0.781 \\
\hline & 16. & Being given tasks with unreasonable or impossible targets or deadlines & 0.780 \\
\hline \multirow{10}{*}{$\begin{array}{l}\text { Personal } \\
\text { bullying }\end{array}$} & 2. & Being humiliated or ridiculed in connection with your work & 0.490 \\
\hline & 5. & Spreading of gossip and rumours about you & 0.562 \\
\hline & 6. & Being ignored or excluded & 0.685 \\
\hline & 7. & $\begin{array}{l}\text { Having insulting or offensive remarks made about your person (ie, habits and } \\
\text { background), your attitudes or your private life }\end{array}$ & 0.747 \\
\hline & 10. & Hints or signals from others that you should quit your job & 0.658 \\
\hline & 12. & Being ignored or facing a hostile reaction when you approach & 0.835 \\
\hline & 13. & Persistent criticism of your errors and mistakes & 0.716 \\
\hline & 14. & Having your opinions and views ignored & 0.442 \\
\hline & 15. & Practical jokes carried out by people you don't get on with & 0.677 \\
\hline & 17. & Having allegations made against you & 0.734 \\
\hline
\end{tabular}

fit indices and a total of nine items loading on the factor person-related bulling and five items loading on work-related bullying. This finding is consistent with findings from the Italian validation of the NAQ-R where two similar factors emerged $^{54}$ and the Japanese version where the two factors of person-related and work-related bullying emerged in addition to a third factor labelled sexual harassment. ${ }^{55}$ It is important to note that two of the employed fit indices (AGFI and CFI) did not reach the set cut-off for model fit hence our findings with regards to factor structure should be

Table 6 Confirmatory factor analysis of the Negative Acts Questionnaire-Revised (NAQ-R) assuming a two-factor solution

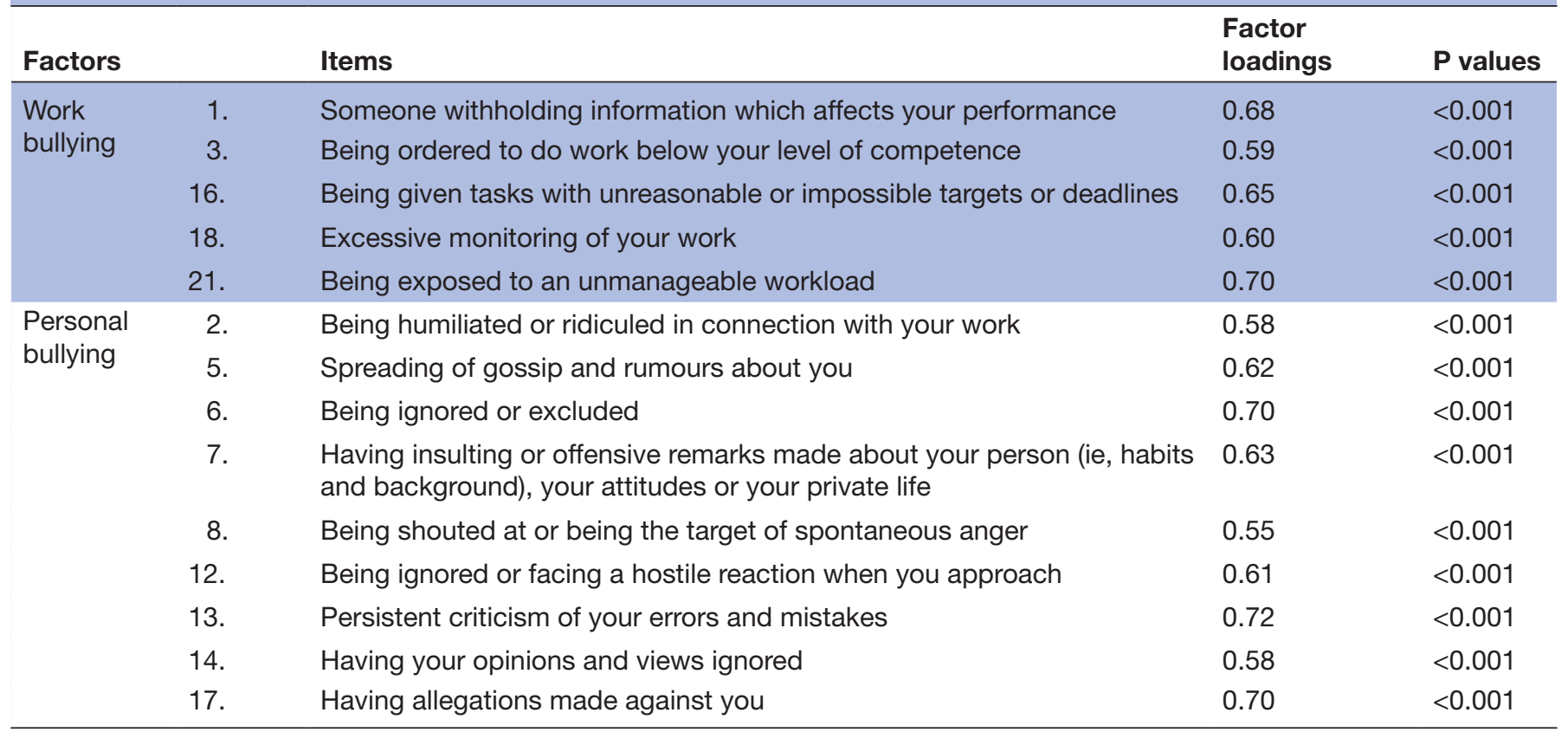


interpreted with caution. It is noteworthy that the subscale physically threatening behaviour obtained the lowest reliability estimate of 0.63 . This is consistent with the study conducted by Giorgi et al whereby items related to physically threatening behaviour obtained low internal consistency coefficients and were thus removed. ${ }^{54}$ They speculated that physical violence was too extreme for their Italian sample and might have been considered as a different phenomenon for them. In the Greek version of the NAQ-R, an item related to physical violence was loaded on the person-related bullying subscale. The authors Charilaos et alstated that this item bears legal and social considerations and is mostly avoided among adults. ${ }^{53}$ Consequently, perhaps the physically threatening behaviours subscale of the Arabic version of NAQ-R obtained the lowest reliability and did not emerge as a subscale in the factor structure of the scale.

Concurrent validity of NAQ-R was assessed through its correlation with depressive symptoms and overall life satisfaction. As hypothesised, the NAQ-R total scores were positively correlated with depression and negatively correlated with life satisfaction.

A number of studies have documented the relationship between depression and workplace bullying. ${ }^{56-59}$ Such a relationship can be explained by the possibility that exposure to bullying may prolong feelings of stress, despair, worry, helplessness, anxiety, confusion and a deteriorated self-esteem, ${ }^{1249}{ }^{57}$ which are common factors known to contribute to depression. ${ }^{59}$ In fact, humiliation resulting from workplace bullying has also been documented as a predictor of depression. ${ }^{60}$ Hence workplace bullying can be considered as a psychosocial contributor to depression. ${ }^{59}$

Nevertheless, it is important to note that several studies asserted the existence of a reciprocal basis for the relationship between workplace bullying and depression. ${ }^{61}$

This is explained by the notion that employees who exhibit depressive and anxious behaviours might start performing poorly at their jobs which may place them in a position of becoming a target to workplace bullying. ${ }^{18}$ From the perspective of attribution theory, high levels of mental distress like depression might lead the depressed individual to attribute hostility to ambiguous behaviours thus leading to increased likelihood of reporting ambiguous acts as bullying. ${ }^{62}$ All in all, it is deduced that depression and workplace bullying interact in a vicious circle. ${ }^{61}$

The negative correlation between workplace bullying and life satisfaction has been confirmed. ${ }^{63}$ It is asserted that workplace bullying is an aetiological factor of mental health problems that the bullied individuals suffer from $;{ }^{61}$ as stated previously, victims of workplace bullying experience lower levels of well-being, lower self-esteem, anxiety, depression and stress symptoms. In addition to the psychological stressors, victims of workplace bullying also suffer psychosomatic symptoms like headaches, fatigue, insomnia, stomach pain, backaches, and lack of energy. ${ }^{731}$ These psychological and psychosomatic symptoms result in stress which in turn is a precursor to lowered life satisfaction. ${ }^{64}$ Stress, burn-out and decreased levels of job satisfaction, which result from workplace bullying, also act as partial mediators for the relationship between workplace bullying and life satisfaction. ${ }^{63}$

In line with previous findings, ${ }^{5065}$ we found that sick leaves were taken up more often by those who reported being bullied. This association may be a function of the exclusion felt by the bullied individual from work life which may in turn increase sick leaves as the individual suffers from a deterioration and impairment of health as a function of bullying. In fact, employees exposed to workplace bullying are more likely to report health complaints than those who are not exposed to it. Therefore, the relationship between workplace bullying and sick leave can be explained in light of workplace bullying's detrimental consequences on the psychological and psychosomatic health of targets. ${ }^{66}$

Concordant with other studies ${ }^{467}$ we found that full-timers reported being bullied more often than part-timers. Fulltime employees are more prone to experience greater work intensity and more responsibility than part-timers which may serve as a vulnerability to bullying exposure ${ }^{68-70}$ However, it is important to note that the opposite pattern has also been found where part-time employment is positively related to workplace bullying. ${ }^{71}$ This can be explained by the fact that sometimes full-timers pressure the part-timers with extreme workload leaving the latter powerless to handle the situation. ${ }^{72}$ Hence, the contradictory results among studies investigating workplace bullying and employment type show that this relationship needs to be targeted with more caution and more focus on the factors that might be corresponding to such differences.

Each of the aforementioned outcomes provides significance to this study in that they provide a better understanding of the factors that might be associated with workplace bullying, thus presenting a foundation on which social and public health interventions can be implemented. Additionally, the outcomes obtained were in concordance with previous studies, further supporting the existing literature on workplace bullying.

A number of strengths pertaining to the study are worth mentioning. This is the first study to yield an Arabic version of the NAQ-R with acceptable levels of reliability and construct validity. This Arabic NAQ-R can be used in more than 25 countries where Arabic is the official/co-official language in addition to assessing workplace bullying among Arabic-speaking immigrants in the West. Additionally, an adequate sample size was used and rigorous methodological process of scale validation was employed including submission of scales to focus groups.

Our study comes with a number of limitations and challenges. One of the major challenges we faced was the recruitment of participants. Data collectors expressed great difficulty in getting supervisors' approval to distribute questionnaires related to workplace bullying to employees during working hours. The presence of supervisors/managers might have also affected the response of participants (response bias) possibly accounting for the low prevalence of self-labelled bullying among 
our sample. In future research, on-line data collection should be employed to bypass this barrier and to ensure anonymity.

In terms of generalisation, our findings should be interpreted with caution because our sample was drawn from one particular area in central Beirut.

Furthermore, cross-cultural factors related to the bullying field is a dimension worth exploring. It is clear that bullying prevalence widely varies between different counties. These differences are accounted for by several factors, one of them being the cultural dimension. ${ }^{29}$ Hence, the addition of organisational climate scales should be addressed in further workplace bullying research to test the influence of the cultural environment of the organisation on the perpetuation of workplace bullying. As much as organisational antecedents are stressed on when investigating the phenomenon of workplace bullying, it is of significance to point to the individual and personality antecedents of workplace bullying so as to be able to understand workplace bullying as a whole. Given that the reaction to workplace bullying can vary from one person to another and not everyone exposed to workplace bullying experiences its negative consequences, this shows that there are personal resources that might be of aid in overcoming workplace bullying. ${ }^{73}$ Among the individual and personality factors, resilience can be considered as a functional resource in overcoming the negative effects of workplace bullying. ${ }^{74}$ With the ability of resilience to act as a mediating factor between workplace bullying and its various side effects, ${ }^{75}$ the results of the study with regard to the correlation between workplace bullying and each of depression, life satisfaction and sick leaves, might have been impacted by some of the participant's possession of a heightened level of resilience; thus, the absence of assessing the resilience factor forms a limitation for the current study and poses the importance of investigating this factor in future research related to workplace bullying.

Finally, negative acts should be considered as a threat to the organisation as a whole and to the health and well-being of its employees. Having a tool that is able to assess the prevalence of workplace bullying among Arabic-speaking employees can prove to be an invaluable strategic tool for organisations and especially for the Arabic-speaking immigrants and refugees that reside and work in Western countries. Identifying and recognising bullying once it exists will place organisations at a completive advantage of early intervention and prevention of workplace bullying.

Contributors GNH conceived and supervised the study. NNM contributed to study design and data collection, and had the main responsibility of writing the paper. LRT-E contributed to study design, statistical analysis and interpretation of the results. DB contributed to literature review and development of the discussion section. SE reviewed and provided valuable feedback and advised on further developing the article.

Funding The authors have not declared a specific grant for this research from any funding agency in the public, commercial or not-for-profit sectors.

Competing interests None declared.
Patient consent Not required.

Ethics approval Institutional Research Board (IRB) at the American University of Beirut - Medical Centre (AUB-MC).

Provenance and peer review Not commissioned; externally peer reviewed.

Data sharing statement № additional data are available.

Open access This is an open access article distributed in accordance with the Creative Commons Attribution Non Commercial (CC BY-NC 4.0) license, which permits others to distribute, remix, adapt, build upon this work non-commercially, and license their derivative works on different terms, provided the original work is properly cited, appropriate credit is given, any changes made indicated, and the use is non-commercial. See: http://creativecommons.org/licenses/by-nc/4.0/.

\section{REFERENCES}

1. Nielsen MB, Matthiesen SB, Einarsen S. The impact of methodological moderators on prevalence rates of workplace bullying. A meta-analysis. J Occup Organ Psychol 2010;83:955-79.

2. Van de Vliert E, Einarsen S, Nielsen MB. Are national levels of employee harassment cultural covariations of climato-economic conditions? Work Stress 2013;27:106-22.

3. Leymann $\mathrm{H}$. The content and development of mobbing at work. European Journal of Work and Organizational Psychology 1996;5:165-84.

4. Einarsen $\mathrm{S}$, Hoel $\mathrm{H}$, Cooper $\mathrm{C}$. Bullying and emotional abuse in the workplace: International perspectives in research and practice : CRC Press, 2003.

5. Niedl K. Mobbing and well-being: economic and personnel development implications. Eur J Work Organ Psychol 1996;5:239-49.

6. Mikkelsen EG, Einarsen S. Relationships between exposure to bullying at work and psychological and psychosomatic health complaints: the role of state negative affectivity and generalized selfefficacy. Scand J Psychol 2002;43:397-405.

7. Vartia MA. Consequences of workplace bullying with respect to the well-being of its targets and the observers of bullying. Scand $J$ Work Environ Health 2001;27:63-9.

8. Visinskaite V. Workplace Bullying: in relation to Self-Esteem, Stress, Life Satisfaction and Cyberbullying, 2015.

9. Tuckey MR, Dollard MF, Hosking PJ, et al. Workplace bullying: the role of psychosocial work environment factors. Int J Stress Manag 2009;16:215-32.

10. Einarsen S, Hoel H, Zapf D, et al. The concept of bullying and harassment at work: the European tradition. Bullying Harass Work Dev theory, Res Pract 2011;2:3-40.

11. Hauge LJ, Skogstad A, Einarsen S. The relative impact of workplace bullying as a social stressor at work. Scand J Psychol 2010;51:426-33.

12. Matthiesen SB, Einarsen S. Psychiatric distress and symptoms of PTSD among victims of bullying at work. Br J Guid Counc 2004;32:335-56.

13. Nielsen MB, Matthiesen SB, Einarsen S. Sense of coherence as a protective mechanism among targets of workplace bullying. J Occup Health Psychol 2008;13:128-36.

14. Leymann $\mathrm{H}$. Mobbing and psychological terror at workplaces. Violence Vict 1990;5:119-26.

15. Einarsen S, Matthiesen S, Skogstad A. Bullying, burnout and wellbeing among assistant nurses. J Occup Heal Saf Aust New Zeal 1998;14:563-8.

16. Vie TL, Glasø L, Einarsen S. How does it feel? Workplace bullying, emotions and musculoskeletal complaints. Scand J Psychol 2012;53:165-73.

17. Kivimäki $M$, Leino-Arjas $P$, Virtanen $M$, et al. Work stress and incidence of newly diagnosed fibromyalgia: prospective cohort study. J Psychosom Res 2004;57:417-22.

18. Rodríguez-Muñoz A, Baillien E, De Witte $\mathrm{H}$, et al. Cross-lagged relationships between workplace bullying, job satisfaction and engagement: Two longitudinal studies. Work Stress 2009;23:225-43.

19. Hogh A, Hoel H, Carneiro IG. Bullying and employee turnover among healthcare workers: a three-wave prospective study. J Nurs Manag 2011;19:742-51.

20. Vingård $\mathrm{E}$, Lindberg $\mathrm{P}$, Josephson $\mathrm{M}$, et al. Long-term sick-listing among women in the public sector and its associations with age, social situation, lifestyle, and work factors: a three-year follow-up study. Scand J Public Health 2005;33:370-5.

21. Hofstede G. Culture's consequences: international differences in work-related values: Sage, 1984.

22. Hofstede G. The cultural relativity of organizational practices and theories. J Int Bus Stud 1983;14:75-89. 
23. Alameddine M, Mourad Y, Dimassi H. A national study on nurses' exposure to occupational violence in Lebanon: prevalence, consequences and associated factors. PLoS One 2015;10:e0137105.

24. Alameddine M, Kazzi A, El-Jardali F, et al. Occupational violence at Lebanese emergency departments: prevalence, characteristics and associated factors. J Occup Health 2011;53:455-64.

25. Adib SM, Al-Shatti AK, Kamal S, et al. Violence against nurses in healthcare facilities in Kuwait. Int J Nurs Stud 2002;39:469-78.

26. Abbas MA, Fiala LA, Abdel Rahman AG, et al. Epidemiology of workplace violence against nursing staff in Ismailia Governorate, Egypt. J Egypt Public Health Assoc 2010;85:29-43.

27. El-Gilany AH, El-Wehady A, Amr M. Violence against primary health care workers in Al-Hassa, Saudi Arabia. J Interpers Violence 2010;25:716-34.

28. Zapf $\mathrm{D}$, Einarsen $\mathrm{S}$, Hoel $\mathrm{H}$, et al. Empirical findings on bullying in the workplace. Bullying Emot Abus Work Int Perspect Res Pract 2003;103125.

29. Ortega A, Høgh A, Pejtersen JH, et al. Prevalence of workplace bullying and risk groups: a representative population study. Int Arch Occup Environ Health 2009;82:417-26.

30. Harvey MG, Heames JT, Richey RG, et al. Bullying: from the playground to the boardroom. J Leadersh Organ Stud 2006;12:1-11.

31. Alswaid E. Workplace bullying among nurses in Saudi Arabia: an exploratory qualitative study: a 152.800 thesis presented in partial fulfilment of the requirements of the degree of Master of Management at Massey University, 2014.

32. Omari M, Sharma M. 4 In the eye of the beholder. Work Abus Incivility Bullying Methodol Cult Perspect 2015;39.

33. Cowie $\mathrm{H}$, Jennifer $\mathrm{D}$, Neto $\mathrm{C}$, et al. Comparing the nature of workplace bullying in two European countries: Portugal and the UK. Transcending boundaries Integr people, Process Syst 2000:128-33.

34. Preda O. Hofstede's dimensions in portugal. Rom Econ Bus Rev 2012;7:62.

35. Einarsen S, Raknes BI. Harassment in the workplace and the victimization of men. Violence Vict 1997;12:247-63.

36. Einarsen S, Raknes B, Matthiesen SB, et al. Bullying and tough interpersonal conflicts: health injurious interaction at the work place. Bergen, Norw stigma Forl 1994.

37. Ma SC, Wang HH, Chien TW. A new technique to measure online bullying: online computerized adaptive testing. Ann Gen Psychiatry 2017;16:26

38. Cakirpaloglu P, Šmahaj J, Cakirpaloglu SD, et al. Šikana na pracovišti a právní ochrana zaměstnancủ v České republice. Psychol a její kontexty 2016;7:19-36.

39. Bernotaite L, Malinauskiene V. Workplace bullying and mental health among teachers in relation to psychosocial job characteristics and burnout. Int J Occup Med Environ Health 2017;30.

40. Pitney WA, Weuve C, Mazerolle SM. Experiences with and perceptions of workplace bullying among athletic trainers in the secondary school setting. J Athl Train 2016;51:709-16.

41. Karatza C, Zyga S, Tziaferi S, et al. Workplace bullying and general health status among the nursing staff of Greek public hospitals. Ann Gen Psychiatry 2016;15:7.

42. Einarsen S, Hoel H, Notelaers G. Measuring exposure to bullying and harassment at work: validity, factor structure and psychometric properties of the Negative Acts Questionnaire-Revised. Work Stress 2009;23:24-44

43. Einarsen S, Hoel H. The Negative Acts Questionnaire: Development, validation and revision of a measure of bullying at work. 10th European congress on work and organisational psychology, Prague, 2001.

44. Bergbom B, Vartia-Vaananen M, Kinnunen U. Immigrants and natives at work: exposure to workplace bullying. Empl Relations 2015;37:158-75.

45. Jackson DL. Revisiting sample size and number of parameter estimates: some support for the N:q Hypothesis. Struct Equ Model 2003:10:128-41.

46. Abdel-Khalek AM. Internal consistency of an arabic adaptation of the beck depression inventory in four Arab countries. Psychol Rep 1998;82:264-6.

47. Abdallah T. The Satisfaction with Life Scale (SWLS): psychometric properties in an arabic-speaking sample. Int $J$ Adolesc Youth 1998;7:113-9.

48. Diener E, Emmons RA, Larsen RJ, et al. The satisfaction with life scale. J Pers Assess 1985:49:71-5.

49. Beck AT, Steer RA, Brown GK. Beck depression inventory-II. San Antonio 1996;78:490-8.
50. Nielsen MB, Indregard AM, Øverland S, et al. Workplace bullying and sickness absence: a systematic review and meta-analysis of the research literature. Scand J Work Environ Health 2016;42:359-70.

51. Hu Li-tze, Bentler PM. Cutoff criteria for fit indexes in covariance structure analysis: Conventional criteria versus new alternatives. Struct Equ Model a Multidiscip J 1999;6:1-55.

52. Bollen KA. Structural equations with latent variables. New York: John Wiley and Sons, 1989.

53. Charilaos K, Michael G, Chryssa B-T, et al. Validation of the Negative Acts Questionnaire (NAQ) in a sample of Greek teachers. Psychology 2015;06:63-74.

54. Giorgi G, Arenas A, Leon-Perez JM. An operative measure of workplace bullying: the negative acts questionnaire across Italian companies. Ind Health 2011;49:686-95.

55. Takaki J, Tsutsumi A, Fujii Y, et al. Assessment of workplace bullying and harassment: reliability and validity of a Japanese version of the negative acts questionnaire. $J$ Occup Health 2010;52:74-81.

56. Gullander M, Hogh A, Hansen ÅM, et al. Exposure to workplace bullying and risk of depression. $J$ Occup Environ Med 2014;56:1258-65.

57. Hansen AM, Hogh A, Persson R, et al. Bullying at work, health outcomes, and physiological stress response. J Psychosom Res 2006;60:63-72

58. Niedhammer I, David S, Degioanni S. Association between workplace bullying and depressive symptoms in the French working population. J Psychosom Res 2006;61:251-9.

59. Rugulies R, Madsen IE, Hjarsbech PU, et al. Bullying at work and onset of a major depressive episode among Danish female eldercare workers. Scand J Work Environ Health 2012;38:218-27.

60. Kendler KS, Hettema JM, Butera F, et al. Life event dimensions of loss, humiliation, entrapment, and danger in the prediction of onsets of major depression and generalized anxiety. Arch Gen Psychiatry 2003;60:789-96

61. Kivimäki M, Virtanen $M$, Vartia $M$, et al. Workplace bullying and the risk of cardiovascular disease and depression. Occup Environ Med 2003;60:779-83

62. Finne LB, Knardahl S, Lau B. Workplace bullying and mental distress - a prospective study of Norwegian employees. Scand J Work Environ Health 2011;37:276-86.

63. Karakus M, İH Cankaya. Öğretmenlerin maruz kaldiklari psikolojïk șiddete iliș̦kin bî̀ modelin sinanmasi examining a model related to mobbing incurred by teachers. J Educ 2012;42:225-37.

64. Trzcieniecka-Green A, Gaczek A, Pawlak A, et al. The sense of life satisfaction and the level of perceived stress in the midwifery profession-a preliminary report. Arch Psychiatry Psychother 2012;3:35-43.

65. Berthelsen M, Skogstad A, Lau B, et al. Do they stay or do they go? Int J Manpow 2011:32:178-93.

66. Hallberg LR-M, Strandmark MK. Health consequences of workplace bullying: experiences from the perspective of employees in the public service sector. Int J Qual Stud Health Well-being 2006;1:109-19.

67. Skogstad A, Matthiesen SB, Einarsen S. Organizational changes: a precursor of bullying at work? Int $J$ Organ THEORY Behav 2007; 10:58-94

68. Burgess J, Connell J. Vulnerable work and strategies for inclusion: an introduction. Int J Manpow 2015;36:794-806.

69. Le Fevre M, Boxall P, Macky K. Which workers are more vulnerable to work intensification? An analysis of two national surveys. Int $J$ Manpow 2015;36:966-83.

70. Fevre R, Robinson A, Jones $\mathrm{T}$, et al. Researching workplace bullying: the benefits of taking an integrated approach. Int $J$ Soc Res Methodol 2010;13:71-85.

71. Neuman JH, Baron R. Workplace violence and workplace aggression: evidence on their relative frequency and potential causes. Aggress Behav 1996;22:161-73.

72. Shangar RU, Yazdanifard R, Bullying W. Boundary for employees and organizational development. Double Blind Peer Rev Int Res J 2014;14.

73. Simons S, Sauer P. An exploration of the workplace bullying experience: coping strategies used by nurses. J Nurses Prof Dev 2013;29:228-32

74. Jackson D, Firtko A, Edenborough M. Personal resilience as a strategy for surviving and thriving in the face of workplace adversity: a literature review. J Adv Nurs 2007:60:1-9.

75. Callegari $\mathrm{C}$, Bertù $\mathrm{L}$, Lucano $\mathrm{M}$, et al. Reliability and validity of the Italian version of the 14-item Resilience Scale. Psychol Res Behav Manag 2016;9:277-84 